\title{
Brine-shrimp Bioassay for Assessment of Anticancer Property of Essential Oils from Spices
}

\author{
Gan B. Bajracharya ${ }^{1}$ and Sarbajna M. Tuladhar ${ }^{2}$ \\ ${ }^{1}$ Nepal Academy of Science and Technology (NAST), Khumaltar, Lalitpur \\ ${ }^{2}$ Research Centre for Applied Science and Technology (RECAST) \\ Tribhuvan University, Kirtipur, Kathmandu \\ e-mail: ganbajracharya@yahoo.com
}

\begin{abstract}
The potential anticarcinogenicity of essential oils from spices was investigated against brine-shrimp (Artemia salina) nauplii. The essential oils were extracted by hydro-distillation. The lethal concentration at the dose levels 10,100 and $1000 \mathrm{ig} / \mathrm{ml}$ displayed high mortality towards actively swarming Artemia. Asafoetida $\left(\mathrm{LC}_{50}=4.64 \times 10^{-23}\right.$ $\mathrm{ig} / \mathrm{ml})$ and cumin oil $\left(\mathrm{LC}_{50}=0.53 \mathrm{ig} / \mathrm{ml}\right)$ were extremely toxic. Essential oils of ajowan, small cardamom, cinnamon, clove, coriander, cubeb, dill, fennel, ginger, mace, nutmeg, long pepper, rosemary, tarragon and thyme were shown high toxicity. While big cardamom oil and black pepper oil were displayed moderate toxicity.
\end{abstract}

Key words: anticancer, Artemia salina, brine-shrimp bioassay, toxicity, essential oil, spice

\section{Introduction}

Cancer research is mainly focused on three aspects: preventive, diagnostic and therapeutic. All of these aspects are equally important. However, the most desirable way of eliminating the impact of cancer is chemoprevention (Wattenberg 1985). Chemoprevention of cancer means prevention of the occurrence of cancer by early administration of a large number of naturally occurring chemopreventive agents that available in foods of plant origin (Loub et al. 1975). Depending on the mechanism of cancer inhibition, the cancer chemopreventive agents are categorized into four. (1) Precursor compounds that prevent the formation of carcinogenesis (Wattenberg 1985). (2) Detoxification agents which inhibit tumourigenesis by increasing detoxification of carcinogens (Rosenbaum 1983). (3) Blocking agents inhibit tumour promotion because of their characteristic antioxidant property either by attacking oxygen radicals or preventing formation of oxygen radicals (Wattenberg 1993). Some non-nutritive natural blocking agents are terpenes, organosulphides, aromatic isothiocyanates, indoles, phenols, flavonoids, tannins etc. (4) Suppressing agents prevent the expansion of initiated cells into tumours by suppressing the neoplastic process otherwise that would become malignant. Some examples of dietary suppressing agents are protease inhibitors, (-)-epigallocatechin gallate etc (Wattenberg 1993).

Microscale bioassay techniques are attractive because of simplicity, rapidity, cost-effectiveness and reasonably reliability, therefore are used extensively for the screening of biological activity of plant materials. The brine-shrimp bioassay, introduced by Meyer et al. (1982), is an in vivo lethality test technique for the prediction of cytotoxicity (McLaughlin. 1991) and pesticidal activity (Ghisalberti 1993). This bioassay technique has been adopted in several publications to explain the anticancer property of several plant materials (Taha et al. 2000; Mohtasheem et al. 2001, Pimentel Montanher et al. 2002; Krishnaraju et al. 2005; Park et al. 2007). 
It is well known that intake of naturally occurring secondary metabolites inhibits carcinogenesis and thereby reduces the incidence of cancer in human beings. Cancer research reveals that $80 \%$ of all cancer may be prevented by adopting a cancer resistant lifestyle and diet (Rosenbaum 1983). In this context, among the plant products, essential oils of spices are of particularly interest. Spices are the natural plants in whole or ground form that used for imparting flavor, aroma and seasoning of foods. They are known as appetizers, preservatives and are virtually indispensable in the culinary art. They posses medicinal properties and used in many herbal preparations (Pruthi 1998, Gurung 2009). The physiological and medicinal importance of spices, for instances, curing infections and caries, protection of mucous irritation, increase of saliva secretion to facilitate starch digestion, fortification of physical capacity, reduction of stroke volume and blood pressure etc. drag serious attention for the researches on spices. Herein the toxicity of essential oils of some spices against brine-shrimp and evaluate them as potential cancer inhibitors has been reported.

\section{Methodology}

Spices for the study were procured from the local market. They were used either fresh or dried and whole or ground or chopped as needed. Chemicals from Qualigens and S. D. Fine-Chem. Ltd. were used. Brineshrimp (Artemia salina) eggs were purchased from Ocean Star International Inc., Snowville, UT, U.S.A. All the glassware, Whatman no. 3 discs and micro pipette tips required for the bioassay were autoclaved at 15 psi pressure for 15 minutes in prior of using.

\section{Procedure}

\section{Extraction of essential oil}

The extraction of essential oils of spices was achieved by hydro-distillation in a Clevenger apparatus (AOAC 1975). Accurately weighed plant material was transferred quantitatively to a round bottom flask of required capacity ( $1 \mathrm{~L}$ or $2 \mathrm{~L}$ ) and filled with distilled water, enough to cover the material. The flask was equipped with the Clevenger apparatus (either heavier than water design or lighter than water design, depending upon the oil density) and heated to a smooth boiling on a heating mantle. The essential oil along with steam was condensed and collected in the trap of the Clevenger apparatus. The hydro-distillation was continued until two consecutive readings taken at an interval of one hour showed no change in the volume of oil in the trap. The whole hydro-distillation set was cooled to room temperature and allowed to stand undisturbed until separation of the clear oil layer. The volume of oil extracted was noted, drained and dried with minimum amounts of anhydrous sodium sulphate.

\section{Preparation of artificial sea water}

Table 1 presents the composition of salts used for the preparation of artificial sea water in double distilled water. The $\mathrm{pH}$ was adjusted to $8.0 \pm 0.2$ by addition of sodium sulphate or sodium bicarbonate as the case may be.

Table 1. Composition of artificial sea water

\begin{tabular}{l|c}
\hline Name of the salt & Amount (g/L of distilled water) \\
\hline $\mathrm{NaCl}$ & 23.50 \\
$\mathrm{Na}_{2} \mathrm{SO}_{4}$ & 4.00 \\
$\mathrm{KCl}$ & 0.68 \\
$\mathrm{H}_{3} \mathrm{BO}_{3}$ & 0.026 \\
$\mathrm{MgCl}_{2} \cdot 6 \mathrm{H}_{2} \mathrm{O}$ & 10.78 \\
$\mathrm{CaCl}_{2}$ (fused) & 1.47 \\
$\mathrm{NaHCO}_{3}$ & 0.196 \\
$\mathrm{Na}_{2} \mathrm{EDTA}$ & 0.0003 \\
\hline
\end{tabular}

\section{Hatching the shrimp}

Brine-shrimp eggs were hatched in artificial sea water (Meyer et al. 1982). A spatula full brine-shrimp eggs was placed in a $1 \mathrm{~L}$ beaker containing $600 \mathrm{ml}$ of freshly prepared artificial sea water. After incubation for 48 hours at warm temperature (29-32 ÚC), the freshly hatched, active phototropic nauplii of about $1 \mathrm{~mm}$ length were separated from the eggs, collected in a petri dish and were used for the bioassay.

\section{Sample preparation}

Meyer's procedure of brine-shrimp bioassay (Meyer et al. 1982) was slightly modified for the preparation 
Gan B. Bajracharya et al./Potential Antibacterial.

of sample by using acetone instead of methanol as dissolving solvent. Solution A was prepared in a volumetric flask of $10 \mathrm{ml}$ capacity by dissolving essential oil $(0.10 \mathrm{~g})$ in acetone up to the mark. Solution $B$ was prepared by diluting $0.5 \mathrm{ml}$ of solution A with acetone to $10 \mathrm{ml}$. Solution B (100 il, for $10 \mathrm{ig} / \mathrm{ml}$ dose level) was transferred to $1.25 \mathrm{~cm}$ disc of Whatman no. 3 , contained in each test tube of $6 \mathrm{ml}$ capacity arranged in five replicates. Next, $50 \mathrm{il} \mathrm{and} 500 \mathrm{il} \mathrm{of} \mathrm{solution} \mathrm{A}$ for $100 \mathrm{ig} / \mathrm{ml}$ and $1000 \mathrm{ig} / \mathrm{ml}$ dose levels, respectively, were transferred to separate discs contained in separate test tubes in five replicates. A control test tube for each dose level was also prepared using the respective volume of acetone alone. The discs were first air dried and then traces of the solvent were evaporated at 37 ÚC under reduced pressure using a rotary evaporator. Thus prepared sample test tubes were immediately used for the bioassay.

\section{Bioassay and calculation}

The brine-shrimp bioassay is a rapid, inexpensive and reliable technique for testing lethality of plant extract because of correlation of cytotoxicity to anticancer property (McLaughlin 1991). The brine-shrimp nauplii can be counted in the stem of a Paster pipette against a lighted background. Ten active shrimps were collected into a measuring cylinder and then transferred into the each test tube of all dose levels. The total volume of the artificial sea water was adjusted to $5 \mathrm{ml}$. Because of five replicates and one control for each dose level, there were altogether eighteen sample test tubes. All the tubes were kept under general room illumination. After 24 hours, the survivors in each tube were counted. Absence of movement of nauplii for 5 minutes was regarded as dead and the percentage death was computed. The $\mathrm{LC}_{50}$ (Lethal Concentration 50) and 95\% CI (Confidence Intervals) were calculated using the Probit Analysis. $\mathrm{LC}_{50}$ is the log concentration for $50 \%$ survival and is determined by using the formulas:

$\mathrm{y}=\alpha+\beta \mathbf{x}$

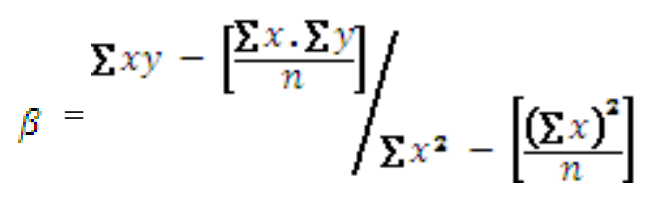

$a=\frac{1}{n}\left(\sum y-\beta \sum x\right)$ where,

$y=5$ (from the Probit Transformation Table)

$\mathrm{n}=$ number of dose levels

$\sum x=$ sum of the $\log$ of doses $\mu \mathrm{g} / \mathrm{ml}$

$\sum y=$ sum of the responses

$\sum x y=$ sum of the values of $x y$

$\sum x^{2}=$ sum of the values of $x^{2}$

$\mathrm{LC}_{50}$ is given by antilog of $\mathrm{x}$ and is denoted by.

$95 \% \mathrm{CI}(\mu \mathrm{g} / \mathrm{ml})$ is the assurance of $95 \%$ guarantee for $50 \%$ survivor, which is calculated by the following relation.

$95 \% \mathrm{CI}=\overline{\mathbf{x}}_{ \pm 1.96}\left(\frac{\sigma}{\sqrt{n}}\right)$

where,

$\sigma($ Standard Deviation $)=\frac{1}{n-1}\left[\sum x^{2}-\frac{\left(\sum x\right)^{2}}{n}\right]$

\section{Results and Discussion}

Table 2 summarizes the results of extraction of essential oils from the spices. The density of cinnamon bark oil and clove oil was greater than water. Freshly hydrodistillated asafoetida oil was yellow in colour and became brown on standing. The oil content of different spices in the decreasing order was clove $(16.0 \%)$, mace (11.8\%), nutmeg (7.0\%), zanthoxylum $(5.06 \%)$, small cardamom (4.5\%), ajowan and cumin $(3.0 \%)$, black pepper (2.5\%), large cardamom (2.0\%), dill (1.6\%), fennel $(1.4 \%)$, rosemary $(1.33 \%)$, cinnamon $(1.2 \%)$, cinnamon bark (1.1\%) and thyme (1.06\%). In other spices studied, the oil content was found below $1 \%$.

The dehydrated essential oils of spices were separately bioassayed against brine-shrimp nauplii. After 24 hours, the percentage death of the nauplii due to the lethality of the essential oil in each dose level was determined. The values are computed using SPSS 16.0 for Windows software (SPSS Inc., Microsoft Corporation) and expressed as the mean $\pm \mathrm{SE}$ (Standard Error) as depicted in Figure 1. As expected, the degree of lethality was found directly proportional to the oil concentration. The mortality rate of Artemia nauplii was drastically increased as the dose level was increased from 10 to $100 \mathrm{ig} / \mathrm{ml}$ and $100 \%$ mortality was observed at $1000 \mathrm{ig} / \mathrm{ml}$ dose level. All the nauplii remained active with no mortality in the control tubes. 
Table 2. Essential oil of the spices

\begin{tabular}{|c|c|c|c|c|c|}
\hline \begin{tabular}{l|} 
S. \\
No.
\end{tabular} & Name of the oil & $\begin{array}{l}\text { Botanical name of the plant material } \\
\text { (Nepali name) }\end{array}$ & Part used (g) & Colour of the oil & $\begin{array}{l}\text { Oil content } \\
(\mathrm{ml}, \%)\end{array}$ \\
\hline 1 & Ajowan $^{[\mathrm{a}]}$ & Trachyspermum ammi (Jwano) & seed (100) & pale yellow & $3.0,3.0$ \\
\hline 2 & Asafoetida $^{[\mathrm{a}]}$ & Ferula asafetida (Hing) & $\begin{array}{l}\text { rhizome exudation } \\
\text { (200) }\end{array}$ & $\begin{array}{l}\text { yellow, brown on } \\
\text { standing }\end{array}$ & $0.9,0.45$ \\
\hline 3 & Cardamom (large $)^{[\mathrm{a}]}$ & Amomum subalatum (Alainchi) & fruit (100) & pale yellow & $2.0,2.0$ \\
\hline 4 & Cardamom (small) ${ }^{[a]}$ & Elettaria cardamomum (Sukumel) & fruit (100) & colourless & $4.5,4.5$ \\
\hline 5 & Cinnamon bark ${ }^{[b]}$ & Cinnamomum zeylanicum (Dalchini) & bark (100) & yellow & $1.1,1.1$ \\
\hline 6 & Cinnamon $^{[\mathrm{a}]}$ & Cinnamomum tamala (Tejpat) & leaf $(100)$ & yellow & $1.2,1.2$ \\
\hline 7 & Clove $^{[b]}$ & Syzygium aromaticum (Lwang) & bud (100) & colourless & $16.0,16.0$ \\
\hline 8 & Coriander ${ }^{[\mathrm{a}]}$ & Coriandrum sativum (Dhania) & seed $(100)$ & colourless & $0.5,0.5$ \\
\hline 9 & Cubeb $^{[\mathrm{a}]}$ & Litsea cubeba (Siltimur) & berry (150) & yellow & $0.6,0.4$ \\
\hline 10 & Cumin $^{[a]}$ & Cuminum cyminum (Jira) & seed $(100)$ & pale yellow & $3.0,3.0$ \\
\hline 11 & $\operatorname{Dill}^{[\mathrm{a}]}$ & Anethum sowa (Nepali sounp) & seed (100) & colourless & $1.6,1.6$ \\
\hline 12 & Fennel $^{[\mathrm{a}]}$ & Foeniculum vulgare (Sounp) & seed (100) & pale yellow & $1.4,1.4$ \\
\hline 13 & Ginger $^{[\mathrm{a}]}$ & Zingiber officinale (Aduwa) & peeled rhizome (300) & yellow & $0.7,0.23$ \\
\hline 14 & Mace $^{[\mathrm{a}]}$ & Myristica fragrans (Jaipatri) & seed $(100)$ & colourless & $11.8,11.8$ \\
\hline 15 & Nutmeg $^{[a]}$ & Myristica fragrans (Jaifal) & kernel (100) & colourless & $7.0,7.0$ \\
\hline 16 & Pepper (black) ${ }^{[\mathrm{a}]}$ & Piper nigrum (Marich) & berry (100) & colourless & $2.5,2.5$ \\
\hline 17 & Pepper (long) ${ }^{[\mathrm{a}]}$ & Piper longum (Thulo pipla) & fruit (300) & yellow & $0.9,0.3$ \\
\hline 18 & Rosemary $^{[a]}$ & Rosmarinus officinalis & leaf $(90)$ & yellow & $1.2,1.33$ \\
\hline 19 & Tarragon $^{[\mathrm{a}]}$ & Artemisia dracunculus & leaf $(100)$ & pale yellow & $0.4,0.4$ \\
\hline 20 & Thyme $^{[\mathrm{a}]}$ & Thymus serpyllum & leaf (75) & light yellow & $0.8,1.06$ \\
\hline 21 & Zanthoxylum $^{\text {[a] }}$ & Zanthoxylum armatum (Timur) & berry (150) & colourless & $7.6,5.06$ \\
\hline
\end{tabular}

${ }^{[a]}$ Lighter than water. ${ }^{[b]}$ Heavier than water. 
Gan B. Bajracharya et al./Potential Antibacterial............
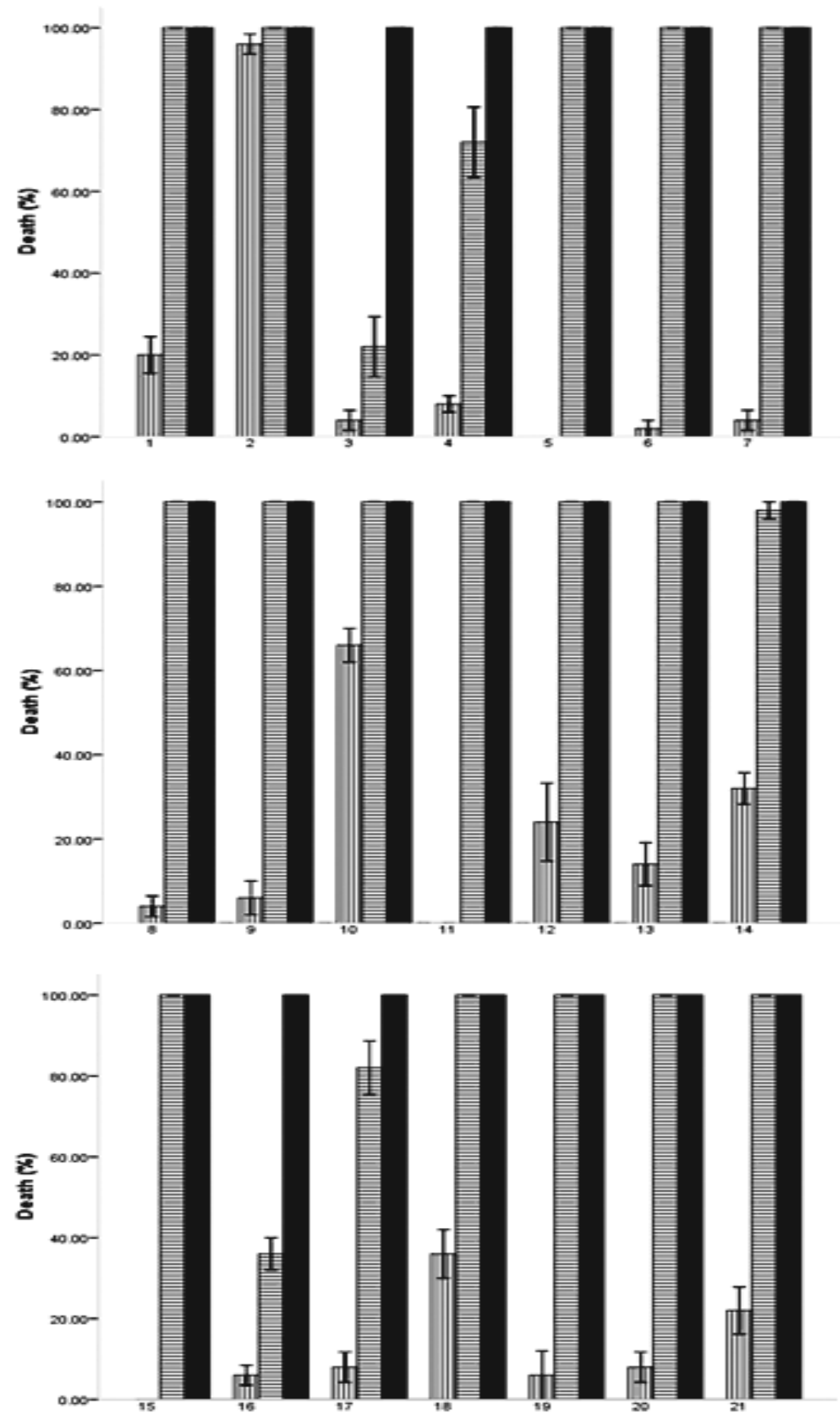

IIIII Dose level $10 \mu \mathrm{g} / \mathrm{ml} \quad \square$ Dose level $100 \mu \mathrm{g} / \mathrm{ml} \quad \square$ Dose level $1000 \mu \mathrm{g} / \mathrm{ml}$

Fig. 1. Percentage death of Artemia nauplii after 24 hours at different dose levels in the bioassay of essential oils: (1) Ajowan, (2) Asafoetida, (3) Cardamom (large), (4) Cardamom (small), (5) Cinnamon bark, (6) Cinnamon, (7) Clove, (8) Coriander, (9) Cubeb, (10) Cumin, (11) Dill, (12) Fennel, (13) Ginger, (14) Mace, (15) Nutmeg, (16) Pepper (black), (17) Pepper (long), (18) Rosemary, (19) Tarragon, (20) Thyme, and (21) Zanthoxylum. 
The values of $\mathrm{LC}_{50}$ and $95 \% \mathrm{CI}$, calculated from the 24 hour counts, are presented in Table 3 . The plant extract displaying $\mathrm{LC}_{50}$ value less than 1000 is considered as pharmacologically active and is toxic. Interestingly, all the essential oils investigated were found toxic against Artemia nauplii indicating their potential anticancer property. The most prominent activity with $\mathrm{LC}_{50}$ value of $4.64 \times 10^{-23} \mathrm{ig} / \mathrm{ml}$ was displayed by asafoetida oil there by possessing more anticancer property, followed by cumin oil $\left(\mathrm{LC}_{50}=0.53 \mathrm{ig} / \mathrm{ml}\right)$.

Table 3. Toxicity of essential oil of spices

\begin{tabular}{|c|c|c|c|c|c|c|}
\hline \multirow{2}{*}{$\begin{array}{c}\text { S. } \\
\text { No. }\end{array}$} & \multirow[t]{2}{*}{ Name of the oil } & \multicolumn{3}{|c|}{ Percentage death at 24 hours/Dose } & \multirow[t]{2}{*}{$\mathrm{LC}_{50}(\mu \mathrm{g} / \mathrm{ml})$} & \multirow[t]{2}{*}{$95 \%$ CI $(\mu \mathrm{g} / \mathrm{ml})$} \\
\hline & & $10 \mu \mathrm{g} / \mathrm{ml}$ & $100 \mu \mathrm{g} / \mathrm{ml}$ & $1000 \mu \mathrm{g} / \mathrm{ml}$ & & \\
\hline 1 & Ajowan & 20 & 100 & 100 & 26.09 & $24.95-27.22$ \\
\hline 2 & Asafoetida & 96 & 100 & 100 & $4.64 \times 10^{-23}$ & $-1.13-1.13$ \\
\hline 3 & Cardamom (large) & 4 & 22 & 100 & 146.77 & $147.91-145.64$ \\
\hline 4 & Cardamom (small) & 8 & 72 & 100 & 60.61 & $59.48-61.75$ \\
\hline 5 & Cinnamon bark & 0 & 100 & 100 & 46.41 & $45.27-47.54$ \\
\hline 6 & Cinnamon & 2 & 100 & 100 & 44.28 & $43.14-45.41$ \\
\hline 7 & Clove & 4 & 100 & 100 & 42.16 & $41.037-43.30$ \\
\hline 8 & Coriander & 4 & 100 & 100 & 42.16 & $41.037-43.30$ \\
\hline 9 & Cubeb & 6 & 100 & 100 & 40.07 & $38.93-41.20$ \\
\hline 10 & Cumin & 66 & 100 & 100 & 0.53 & $-0.60-1.66$ \\
\hline 11 & Dill & 0 & 100 & 100 & 46.41 & $45.27-47.54$ \\
\hline 12 & Fennel & 24 & 100 & 100 & 1.81 & $0.67-2.94$ \\
\hline 13 & Ginger & 14 & 100 & 100 & 31.90 & $30.776-33.03$ \\
\hline 14 & Mace & 32 & 98 & 100 & 16.43 & $15.29-17.56$ \\
\hline 15 & Nutmeg & 0 & 100 & 100 & 46.41 & $45.27-47.54$ \\
\hline 16 & Pepper (black) & 6 & 36 & 100 & 113.58 & $112.45-114.71$ \\
\hline 17 & Pepper (long) & 8 & 82 & 100 & 51.30 & $50.16-52.43$ \\
\hline 18 & Rosemary & 36 & 100 & 100 & 12.71 & $11.57-13.84$ \\
\hline 19 & Tarragon & 6 & 100 & 100 & 40.07 & $38.93-41.20$ \\
\hline 20 & Thyme & 8 & 100 & 100 & 37.99 & $36.85-39.12$ \\
\hline 21 & Zanthoxylum & 22 & 100 & 100 & 24.24 & $23.11-25.37$ \\
\hline
\end{tabular}

It is clear from Table 3 that essential oils of all the spices investigated are toxic against brine-shrimp. Based on the obtained data of $\mathrm{LC}_{50}$ values, the essential oils from the spices are classified according to the strength of toxicity to express their potential anticarcinogenicity (Table 4).

Table 4. Classification of the toxicity of essential oil of spices

\begin{tabular}{|c|c|c|}
\hline LC $_{50}$ values & Classification & Essential oils \\
\hline$<1$ & extremely toxic & asafoetida and cumin \\
\hline $1-100$ & very highly toxic & $\begin{array}{l}\text { ajowan, small cardamom, cinnamon bark, cinnamon, clove, coriander, cubeb, } \\
\text { dill, fennel, ginger, mace, nutmeg, long pepper, rosemary, tarragon, thyme and } \\
\text { zanthoxylum }\end{array}$ \\
\hline $100-200$ & highly toxic & big cardamom and black pepper \\
\hline $200-500$ & moderately toxic & none \\
\hline $500-1000$ & low toxic & none \\
\hline$>1000$ & practically non-toxic & none \\
\hline
\end{tabular}


Gan B. Bajracharya et al./Potential Antibacterial..

Although the brine-shrimp bioassay alone is inadequate to evaluate the anticarcinogenic property, however, it is reasonably reliable to screen the bioactivity of plant materials. Even though, our prescreening results show that the essential oils of the spices that available in the local markets are highly toxic against brine-shrimp and hence are cancer preventive agents. The $\mathrm{LC}_{50}$ value $<1$ is found in asafoetida oil and cumin oil, hence are considered as extremely toxic and are potential for cancer prevention. Essential oils of ajowan, small cardamom, cinnamon bark, cinnamon, clove, coriander, cubeb, dill, fennel, ginger, mace, nutmeg, long pepper, rosemary, tarragon, thyme and zanthoxylum have potentially very high toxicity. Big cardamom oil and black pepper oil are also highly toxic. Further works to standardize the quality of the spices of nepali origin and study on their potent cytotoxic constituents are worthy.

\section{Acknowledgements}

Ministry of Science and Technology, Government of Nepal is gratefully acknowledged for financial support to this research work.

\section{References}

AOAC. 1975. Official Methods of Analysis, $12^{\text {th }}$ edition, Association of Official Analytical Chemistry, pp. 555.

Ghisalberti, E. L. 1993. Detection and isolation of bioactive natural products. In: Bioactive Natural Products: Detection, Isolation and Structure Elucidation (Eds. S. M. Colegate and R. J. Molyneux). Boca Raton: CRC Press. pp. 15-18.
Gurung, K. 2009. Essential Oils in Nepal: A Practical Guide to Essential Oils and Aromatherapy, Himalayan Bio Trade Pvt. Ltd., Kathmandu, Nepal.

Krishnaraju,A. V., T. V. N. Rao, D. Sundararaju, M. Vanisree, H.-S. Tsay and G. V. Subbaraju 2005. Int. J. Appl. Sci. Eng. 3: 125

Loub, W. D., L. W. Wattenberg and D. W. Davis 1975. J. Natl. Cancer Inst. 54: 985.

McLaughlin, J. L. 1991. Methods Plant Biochem. 6: 1.

Meyer, B. N., N. R. Ferrigni, J. E. Putnam, L. B. Jacobsen, D. E. Nichols and J. L. McLaughlin 1982. Planta Medica. 45: 31.

Mohtasheem, M., S. W. Ahmad, I. Azhar and M. S. Ali 2001. Pak. J. Pharmaceutical Sciences, 14: 19.

Park, T.-G., C. J. S. Bolch and G. M. Hallegraeff 2007. J. Plankton Res. 29: 791.

Pimentel Montanher, A. B., M. G. Pizzolatti and I. M. Costa Brighente 2002. Acta Farm. Bonaerense. 21: 175 .

Pruthi, J. S. 1998. Spices and Condiments, $5^{\text {th }}$ edition, National Book Trust, India.

Rosenbaum, E. H. 1983. Can You Prevent Cancer? The C. V. Mosby Company, St. Louis, Toronto.

Taha, A. and H. Alsayed 2000. Phtothe. Res. 14: 48.

Wattenberg, L. W. 1985. Cancer Res. 45: 1, and references therein.

Wattenberg, L. W. 1993. Inhibition of carcinogenesis by non-nutrient constituents of the diet. In: Food and Cancer Prevention: Chemical and Biological Aspects (Eds. K. W. Waldron, I. T. Johnson and G. R. Fenwick). The Royal Society of Chemistry, Cambridge. pp 12-23. 
Nepal Journal of Science and Technology 12 (2011) 163-170 